\title{
An indirect method of attitude measurement
}

\author{
JOSEPH M. MADDEN and ELLEN J. MARTIN \\ Rensselaer Polytechnic Institute, Troy, New York 12181
}

\begin{abstract}
In three experiments, attitudes were measured using a direct method and then measured using an indirect method of profile rating. In two of the experiments, interaction effects were detected, indicating that the hypothesized bias is not present as a main effect but is a function of contextual factors. In a third experiment, main effects not disclosed by a direct method were observed. The profile rating method appears useful for the detection of bias not revealed by direct methods and for specification of some of the complex conditions under which bias will occur.
\end{abstract}

Indirect methods of attitude measurement have been developed to obtain spontaneous attitude data that are not subject to distortion in terms of social desirability. Another potential of the indirect method is the discovery of attitudes that an individual possesses but that are not in the realm of his awareness. Both possibilities possess significant implications for organizational, as well as individual, diagnosis. However, the methods that have been proposed previously usually have some disadvantage that limits their usefulness.

The Bogus Pipeline (Jones \& Segall, 1971) requires large and imposing apparatus, runs only one subject at a time, and is time consuming. Also, with widespread use, naive subjects would be difficult to find. The Proverb Test (Baumgarten, 1952) is interesting but has not stimulated developmental research. Projective tests (Proshansky, 1943; Sanford, 1950) are only rather thinly supported by data. Behavioral methods (La Piere, 1934; Melton, 1933; Wrightsman, 1969) are impressive but have a very limited scope of application. The sentence completion method (Friesen, 1952) also lacks concrete data to demonstrate its effectiveness. The lostletter technique (Milgram, Mann, \& Harter, 1965) is interesting but cumbersome. Use of the galvanic skin response (Cooper \& Pollack, 1959) has demonstrated the affective components of prejudicial attitudes but must be administered to one subject at a time. The pupillary response (Hess, 1965; Hess, Seltzer, \& Shlien, 1965; Woodmansee, 1970) shows promise but is also individually administered. The direction of perception or error-choice technique (Bernberg, 1951; Hammond, 1948; Newcomb, 1946; Selltiz, Jahoda, Deutsch, \& Cook, 1959; Thistlewaite, 1950) seems to have some potential but has not stimulated much interest. Item displacement (Dawes, Singer, \& Lemons, 1972; Hovland \& Sherif, 1952; Selltiz, Edrich, \& Cook, 1965) has some interesting possibilities but offers some difficult design problems.

Requests for reprints should be addressed to Joseph $\mathbf{M}$. Madden, Department of Psychology, Rensselaer Polytechnic Institute, Troy, New York 12181.
What seems to be needed is a method that may be group administered, fits a wide range of problem areas, is not too time consuming, but that is a sensitive detector of attitudes as they exist. At the same time, it would be desirable to identify a method that minimizes possible criticism on an ethical basis because of deception of subjects or for other reasons.

The profile rating method seems to possess the necessary potential. It requires that the subject rate a series of profiles, each consisting of a set of levels on a series of variables. For instance, if we were interested in measuring the effect of supervisory style on attitudes toward supervision in general, with supervisory style ranging from "very autocratic" (1) to "very democratic" (10), we might use such variables as clarity of instructions, considerateness, fairness, and helpfulness, as well as supervisory style. Each profile would then consist of five values indicating the degree to which a supervisor possesses each of the five qualities, and a number of these profiles would be generated. We can now select some number of profiles from the series to be rated and duplicate them so that they appear twice in the series. In each pair of duplicated profiles, the values on the first four variables would be identical. The value for supervisory style in one case of a pair might be, say, a 9; in the other profile in a pair it could be a 2 . Workers would then rate each profile in terms of how desirable they find the supervisor described by the profile. To test the hypothesis, the analysis would examine differences in worker ratings of the pairs of profiles. If there is a significant difference, we would have some confidence in the conclusion that supervisory style is a significant determiner of attitude toward supervision in general. We would also be interested in examining interaction effects. Instead of supervisory style, it would be a simple matter to generate other variables depending on the attitudes of interest. Such variables as sex, race, age, nationality, religion, and attractiveness could easily be used to test hypotheses centering on prejudice or bias.

This paper reports three experiments designed to evaluate the profile rating method. 


\section{METHOD}

\section{Experiment 1}

Male college students $(N=175)$ were instructed that they were participating in research designed to illuminate decisionmaking behavior when voting for a congressional candidate. Each subject divided 100 points among 20 personal qualities as they would to optimize their vote for a candidate. The seven variables with the highest mean scores were chosen to generate the profiles. It is important to note that the variables male, female, and attractive all received mean ratings of less than one point, indicating that the voters feel that these variables contribute very little or nothing to their voting decision when a direct method is used.

Next, 82 male college students distributed 100 points among the seven variables in the same way as on the first administration. Forty-five profiles were randomly selected from the 82 and 5 were randomly selected from the 45 to serve as duplicates, making five pairs of identical profiles. An eighth variable, sex, was then added to all profiles. One of each pair of identical profiles was identified as male, the other female. Half of the remaining 40 profiles were identified as male, the other half female, on an odd-even sorting procedure, and all 50 profiles were then arranged in random order. Finally, 143 male college students rated all 50 profiles on a scale of 1 to 10 , according to the likelihood that they would vote for the candidate depicted by the profile.

\section{Experiment 2}

Male college students $(\mathrm{N}=71)$ were asked to allocate 100 points among five dimensions so as to characterize an individual they would choose to work with on a class project. The five dimensions were honest, hard worker, intelligent, warm, and attractive. The lowest mean number of points (6.06) was assigned to attractive. Forty-five different profiles were randomly selected from the $71 ; 5$ of these were randomly selected to serve as duplicates. In each pair of duplicates, the attractive dimension was varied. For the low-attractive condition, the number of points ranged from 0 to 5 ; for the high-attractive condition, the number of points ranged from 20 to 30 . The mean difference between low- and high-attractive conditions was 24 points. Male students $(\mathrm{N}=44)$ then rated each of the 50 profiles on a scale of 1 to 10 on the basis of their desire to work with each of the students as represented by the profiles.

\section{Experiment 3}

The method was the same as Experiment 2 except that the variable attractiveness was replaced by sex. Half of the profiles were randomly assigned male and half female except for the five pairs of duplicates. One profile in each of these pairs was assigned male and the other female. Male students $(N=43)$ rated the 50 profiles on the same basis as in Experiment 2.

\section{RESULTS}

For each experiment, an analysis of variance was performed using the 10 ratings given by each subject to the five pairs of profiles, so that each subject served as his own control. Thus, there was a randomized-block factorial model in which the subjects were the blocks.

\section{Experiment 1}

Table 1 gives the results of the analysis of variance. There was no main effect for sex, but there was a significant interaction between sex of the profile and the
Table 1

Analysis of Variance for Experiment 1

\begin{tabular}{lrrrr}
\hline \multicolumn{1}{c}{ Source } & \multicolumn{1}{c}{ SS } & df & \multicolumn{1}{c}{ MS } & \multicolumn{1}{c}{ F } \\
\hline Sex (1) & 5.79 & 1 & 5.79 & $2.33 \dagger$ \\
Profiles (2) & 162.54 & 4 & 40.64 & $9.93^{*}$ \\
Subjects (3) & $2,362.24$ & 142 & 16.64 & $6.76^{*}$ \\
1 by 2 & 77.14 & 4 & 19.29 & $7.83^{*}$ \\
1 by 3 & 352.81 & 142 & 2.48 & $1.01 \dagger$ \\
2 by 3 & $2,325.06$ & 568 & 4.09 & $1.66^{*}$ \\
1 by 2 by 3 & $1,398.26$ & 568 & 2.46 & \\
\hline
\end{tabular}

${ }^{*} p<.01$ †Nonsignificant

Table 2

Mean Ratings for the Five Paired Profiles in the Male and Female Conditions, Experiment 1

\begin{tabular}{lccccc}
\hline & \multicolumn{5}{c}{ Profile Number } \\
\cline { 2 - 6 } & 4 & 1 & 5 & 2 & 3 \\
\hline Male & 5.4 & 5.6 & 5.8 & 6.2 & 6.3 \\
Female & 5.7 & 4.9 & 6.2 & 6.1 & 5.7 \\
\hline
\end{tabular}

Table 3

Analysis of Variance for Experiment 2

\begin{tabular}{lrrrc}
\hline \multicolumn{1}{c}{ Source } & \multicolumn{1}{c}{ SS } & df & \multicolumn{1}{c}{ MS } & \multicolumn{1}{c}{ F } \\
\hline Attractiveness (1) & 3.46 & 1 & 3.46 & $.69 \dagger$ \\
Profiles (2) & 852.56 & 4 & 213.14 & $35.74^{*}$ \\
Subjects (3) & 462.10 & 43 & 10.75 & $6.87^{*}$ \\
1 by 2 & 20.85 & 4 & 5.21 & $3.33^{* *}$ \\
1 by 3 & 214.24 & 43 & 4.98 & $3.19^{*}$ \\
2 by 3 & $1,025.64$ & 172 & 5.96 & $3.81^{*}$ \\
1 by 2 by 3 & 268.95 & 172 & 1.56 & \\
\hline
\end{tabular}

$* p<.01 \quad * * p<.05 \quad$ tNonsignificant

Table 4

Mean Ratings for the Five Paired Profiles Under the Attractive and Unattractive Conditions, Experiment 2

\begin{tabular}{cccccc}
\hline \multirow{2}{*}{$\begin{array}{c}\text { Attractive- } \\
\text { ness }\end{array}$} & 1 & 4 & 5 & 3 & 2 \\
\cline { 2 - 6 } & 1 & 5.75 & 5.68 & 6.89 & 7.34 \\
Low & 3.16 & 5.30 & 6.61 & 7.71 \\
High & 3.91 & 5.18 & 5.30 & \\
\hline
\end{tabular}

profile itself. Table 2 gives the mean rating for each of the five paired profiles under the male and female conditions and shows the ratings for female profiles varying around the judgments for male profiles.

\section{Experiment 2}

Table 3 gives the results of the analysis of variance for Experiment 2. Again, a significant interaction was seen between attractiveness of the profile and the profile itself. Table 4 gives the mean ratings for the five paired profiles under the attractive and unattractive conditions.

\section{Experiment 3}

Table 5 gives the results of the analysis of variance for Experiment 3. Here, a significant main effect for sex was observed. No interpretable interaction effects 
Table 5

Analysis of Variance for Experiment 3

\begin{tabular}{lrrrr}
\hline Source & \multicolumn{1}{c}{ SS } & df & \multicolumn{1}{c}{ MS } & \multicolumn{1}{c}{ F } \\
\hline Sex $(1)$ & 13.79 & 1 & 13.79 & $8.28^{*}$ \\
Profiles (2) & 435.09 & 4 & 108.77 & $15.05^{*}$ \\
Subjects (3) & 462.10 & 42 & 11.00 & $5.90^{*}$ \\
1 by 2 & 5.27 & 4 & 1.32 & $.71 \dagger$ \\
1 by 3 & 69.91 & 42 & 1.67 & $.90 \dagger$ \\
2 by 3 & $1,214.51$ & 168 & 7.23 & $3.88^{*}$ \\
1 by 2 by 3 & 313.53 & 168 & 1.87 & \\
\hline
\end{tabular}

${ }^{*} p<.01$ †Nonsignificant

approached significance. For all five pairs of profiles, the mean rating was higher when sex was female than when it was male.

\section{DISCUSSION}

Robustness of the profile rating method is suggested by the results of Experiments 1 and 2, even though these results did not indicate a direct bias toward sex or attractiveness. The detection of interaction effects appears even more interesting than if a simple bias had been observed. Further research would be necessary to specify the conditions under which females are rated higher or lower than males. One speculation that is hard to resist as a result of inspection of the data is that if two political candidates possess high degrees of those attributes the voter considers important, the female stands an equal or better chance with the male. When the caliber of the candidate departs from the voter's ideal, prejudices come into play and the male candidate is favored.

Experiment 2 produced results similar to Experiment 1 when attractiveness was used instead of sex. It appears that when the levels on the variables other than attractiveness were high, the importance of the attractiveness variable diminished. As the levels of the other variables decrease, the importance of attractiveness appears to increase. Further research is indicated to investigate this possibility.

One interesting aspect about the results of Experiments 1 and 2 is the likelihood that the interaction effects detected could not have been expressed by the raters. Such interaction effects are not likely to be a matter of awareness for most people. If the method can be used for no other purpose than bringing into one's awareness some of the determining factors in one's own judgment behavior, it would seem to have a high degree of merit.

In Experiment 3, a rather definite bias in favor of females was detected, even though it was not revealed by the direct method. This bias is not surprising in our predominately male university; however, it is a rather nice test of the power of the profile rating method. Male students gave a socially correct answer when approached with a direct method but revealed a bias when the indirect method was used. In Experiments 1 and 2 , it is impossible to know if the main effects or the hypothesized bias really existed. Therefore, we do not know if it existed and was undetected or whether it was nonexistent in the first place. In Experiment 3, though, we are dealing with a choice of a co-worker in a school where the ratio of women to men is about $1: 12$. In this situation, it is not difficult to accept that a preference for females as co-workers is highly likely. If this notion is acceptable, we see that the indirect method of attitude measurement using profile rating as described here is a useful and powerful tool that merits further study and development.

\section{REFERENCES}

Baumgarten, F. A proverb test for attitude measurement. Personnel Psychology, 1952, 5, 249-261.

BERnBerg, R. E. The direction of perception technique of attitude measurement. International Journal of Opinion and Attitude Research, 1951, 5, 397-407.

Cooper, J. B., \& Pollock, D. The identification of prejudicial attitudes by the galvanic skin response. Journal of Social Psychology, 1959, 50, 241.

Dawes, R. M., Singer, D., \& Lemons, F. An experimental analysis of the contrast effect and its implications for intergroup communication and the indirect assessment of attitude. Journal of Personality and Social Psychology, 1972, 21, 281.

Friesen, E. P. The incomplete sentences technique as a measure of employee attitudes. Personnel Psychology, 1952, 5, 329-345.

Hammond, K. R. Measuring attitudes by error-choice: An indirect method. Journal of Abnormal and Social Psychology, 1948, 43, 38-48.

Hess, E. H. Attitude and pupil size. Scientific American, 1965, 212, 46.

Hess, E. H., Seltzer, A. L., \& Shimen, J. M. Pupil response of hetero- and homosexual males to pictures of men and women: A pilot study. Journal of Abnormal Psychology, 1965, 70, 165-168.

Hovland, C. I., \& Sherif, M. Judgmental phenomena and scales of attitude measurement: item displacement in Thurstone scales. Journal of Abnormal and Social Psychology, 1952, 47, 822.

Jones, E. E., \& Sigall, H. The bogus pipeline: A new paradigm for measuring affect and attitude. Psychological Bulletin, 1971, 76, 349-364.

LA Piere, M. Attitudes vs. actions. Social Forces, 1934, 13, 230.

Melton, A. W. Some behavior characteristics of museum visitors. Psychological Bulletin, 1933, 30, 720-721.

Milgram, S., Mann, L., \& Harter, S. The lost-letter technique of social research. Public Opinion Quarterly, 1965, 29, 437-438.

Newcoms, T. M. The influence of attitude climate upon some determinants of information. Journal of Abnormal and Social Psychology, 1946, 41, 291-302.

Proshansky, H. A projective method for the study of attitude. Journal of Abnormal and Social Psychology, 1943. 38, 393-395.

SANFord, F. H. The use of a projective device in attitude surveying. Public Opinion Quarterly, 1950, 14, 697-709.

Selltiz, C., Edrich, H., \& Cook, S. W. Ratings of favorableness of statements about a social group as an indicator of attitude toward the group. Journal of Personality and Social Psychology, 1965, 2, 408.

Selltiz, C., Jahoda, M., Deutsch, M., \& Cook, S. W. Research Methods in Social Relations. New York: Holt, Rinehart, \& Winston, 1959.

Thistlewarte, D. Attitude and structure as factors in the distortion of reasoning. Journal of Abnormal and Social Psychology, 1950, 45, 442-458.

Woodmansee, J. J. The pupil response as a measure of social attitudes. In G. F. Summers (Ed.), Attitude measurement. New York: Rand McNally, 1970.

Wrightsman, L. S. Wallace supporters and adherence to "law and order." Journal of Personality and Social Psychology, 1969, 13, 17-22.

(Received for publication June 6, 1978.) 